\title{
TRATAMIENTO DE AGUAS PARA EL CONSUMO HUMANO
}

Artículo de reflexión - Recibido: 20 de Marzo de 2014 - Aceptado: 24 de Abril de 2014

\section{Eduard Salamanca²}

Universidad de Manizales. Manizales, Colombia. eduardsalmanca@gmail.com

Para citar este artículo / to reference this article:

Salamanca, E. (2016). Tratamiento de aguas para el consumo humano. Módulo Arquitectura CUC, Vol.17 N¹, 29-48.

\section{Resumen}

Este artículo presenta una reflexión acerca de los procesos de tratamiento del agua para el abastecimiento y el consumo humano, los cuales no solo tienen un componente técnico, sino que influyen en todos los ámbitos desde lo social, lo económico, lo ambiental. El objetivo primordial es el reconocer cuales son las técnicas y métodos más importantes para el tratamiento de aguas para el abastecimiento y consumo humano. Al ser el agua un elemento natural vital para el sustento de toda forma de vida en el planeta tierra, tiene múltiples utilidades tanto en los procesos biológicos como en las diferentes utilidades que el ser humano le da, para ello se han diseñado diferentes utilidades y sistemas de valoración de este recurso. Estos procesos de tratamiento del agua para el abastecimiento son generalmente una secuencia de operaciones o procesos unitarios, convenientemente seleccionados con el fin de remover totalmente los contaminantes microbiológicos presentes en el agua cruda y parcialmente los físicos y químicos, hasta llevarlos a los límites aceptables estipulados por las normas. Finalmente se hace un análisis y discusión de la problemática del agua, articulando factores sociales, económicos, técnicos, culturales, ecológicos, políticos y legislativos.

\section{Palabras clave}

Agua, recurso natural, tratamiento, sostenibilidad. 


\title{
WATER TREATMENT FOR HUMAN CONSUMPTION
}

\begin{abstract}
This article presents a reflection about the processes of water treatment for the supply and the human consumption, which not only have a technical component, but also influence in all the social, economic, environmental. The main objective is to recognize the most important techniques and methods for the treatment of water for human consumption and supply. Since water is a natural element vital to the sustenance of all life on planet earth, it has multiple uses both in the biological processes and in the different utilities that the human being gives to it, for it have been designed different utilities and systems Of valuation of this resource. These water treatment processes for the supply are generally a sequence of operations or unit processes, suitably selected in order to completely remove the microbiological contaminants present in the raw water and partly the physical and chemical ones, to the acceptable limits stipulated by the rules. Finally, an analysis and discussion of the water problem is made, articulating social, economic, technical, cultural, ecological, political and legislative factors.
\end{abstract}

\section{Keywords}

Water, natural resource, treatment, sustainability. 


\section{Introduccion}

Las tres terceras partes de nuestro planeta están formadas por agua; sin embrago no toda esta agua la podemos utilizar los humanos, esto debido a que el $97 \%$ del agua presente en el planeta se encuentra en los mares y por su composición salada no es apta para nuestro consumo y para gran variedad de especies animales y de plantas que se encuentran en la superficie de la tierra, adicionalmente se encuentra un $2 \%$ del agua dulce en acuíferos subterráneos y en los glaciares, conformándose en reservorios de vida y del líquido como tal a los cuales no podemos tener acceso directamente para la utilización en los diferentes procesos ya sea biológicos o de carácter antrópico por parte del hombre. El agua es uno de los compuestos más abundantes en la naturaleza ya que cubre aproximadamente tres cuartas partes de la superficie total de la tierra. Sin embargo y a pesar de la aparente abundancia, existen diferentes factores que limita la cantidad de agua disponible para el consumo humano. El 97\% del total de agua en el mundo, corresponde al de los océanos y otros cuerpos de agua salina y no se puede utilizar para diversos propósitos. Del restante $3 \%$, casi el $2 \%$ se encuentra distribuida en los témpanos de hielo, glaciares, en la atmosfera o mezclada con el suelo, por lo que no es accesible. Por consiguiente el total de agua útil para el desarrollo y sostenimiento de la vida humana con sus actividades industriales y agrícolas, se dispone aproximadamente de $0,62 \%$ del agua restante, que se encuentra en lagos de agua fresca, ríos y mantos freáticos (Arellano, 2002). El agua dulce es imprescindible para la vida. Todo ser humano necesita de ella, así pues, todas las personas de la tierra demandan, al menos, una mínima cantidad. Desde un punto de vista mercantil, el agua es un producto con una gran demanda, por lo tanto, el agua dulce es un gran negocio que debe regirse por las leyes del mercado. Según esta visión mercantil, la mala distribución de los recursos hídricos, su desperdicio y la contaminación son males achacables únicamente a los Estados. La escasez de agua en algunas regiones del mundo está "ayudando" a que ésta se convierta en una mercancía inmensamente deseable, y las empresas de agua han logrado persuadir a la mayoría de los gobiernos a adoptar un enfoque comercial.

En realidad solo tenemos disponible para nuestro uso y el de todas las especies animales y plantas terrestres solo el $1 \%$ del agua del planeta, por lo 
tanto se debería racionalizar y hacer una gestión integral de este recurso; sin embrago lo que observamos en la realidad es que el agua se contamina a diario por nosotros mismos, situación que podríamos controlar o disminuir si se realizaran procesos de descontaminación del agua contaminada que generamos antes de que esta retorne a las fuentes hídricas de las cuales posteriormente nosotros mismo vamos a necesitar ya sea como fuente para consumo humano, empresarial o en la agricultura. Las diversas actividades agrícolas, ganaderas, industriales y recreacionales del ser humano han traído como consecuencia la contaminación de las aguas superficiales con sustancias químicas y microbiológicas, además del deterioro de sus características estéticas. El tratamiento de aguas está regido por una serie de normas que indican o fijan los límites generales aceptables para las impurezas de las aguas que están destinadas al abastecimiento público (condiciones mínimas de calidad física, química y bacteriológica) (Canto, 1977). Estas normas no deben considerarse como un criterio que evaluación o control de las operaciones de las plantas de tratamiento sino como las especificaciones generales para cuando el tratamiento de las aguas está bien controlado, se pueden obtener mejores resultados que los establecidos en las normas. Existen distintos tipos de tratamiento de las aguas para lograr remover los contaminantes. Se pueden usar desde sencillos procesos físicos como la sedimentación, en la que se deja que los contaminantes se depositen en el fondo por gravedad, hasta complicados procesos químicos, biológicos o térmicos. Ellos se pueden clasificar según el medio de eliminación de los contaminantes, según la fase de depuración y según el costo de la explotación.

En muchos países del mundo, el agua dulce es antes un "bien público" que un Derecho fundamental del ser humano. Al permitir que el acceso y la distribución de agua sean dirigidos por mercados insaciables, la crisis mundial del agua seguramente se profundizará y el acceso al agua será aún más desigual. En la actualidad muchos gobiernos llegaron a acuerdos con el sector privado, con el argumento de poder así resolver los problemas de acceso al agua de muchos millones de personas (Agencia Andaluza de Cooperación Internacional para el Desarrollo, 2013). En cuanto al consumo humano 
es importante resaltar que se hace necesario la utilización del agua en óptima calidad, por lo cual se han diseñado procesos que permiten la descontaminación de este recurso, mediante la evaluación del agua en diferentes tablas que establecen el grado de calidad que tienen determinada agua y si esta es a su vez apta para el consumo humano; para ello es importante hacer monitoreo de este líquido desde que se toma en las fuentes hídricas has que llega a nuestros hogares y es consumida o utilizada en los diferentes procesos en los cuales hacemos uso de ella.

\section{El Agua}

Para hablar de tratamiento de aguas para el consumo humano, debemos primero definir algunos elementos importantes como recurso conceptual en términos de: parámetros fisicoquímicos y biológicos del agua, calidad del agua, contaminación y tratamiento del agua. Igualmente conocer cuales procesos se llevan acabo entorno a su uso y cuales para los procesos de tratamiento.

Parámetros físicos de la calidad del agua: Estos son los que definen las características del agua que responden a los sentidos de la vista, el tacto, gusto y olfato como por ejemplo: los sólidos suspendidos, turbiedad, color, sabor, olor y temperatura. Parámetros químicos de la calidad del agua: El agua es Ilamada el solvente universal y los parámetros químicos están relacionados con la capacidad del agua para disolver diversas sustancias entre las que podemos mencionar a los sólidos disueltos totales, alcalinidad, dureza, fluoruros, metales, materia orgánica y nutriente (Arellano, 2002).

Parámetros biológicos de la calidad del agua: En el agua literalmente hablando es un medio donde habitan especies biológicas diversas y llevan a cabo su ciclo vital. Desde el organismo unicelular hasta especies de gran tamaño, evidencian la calidad del agua, su presencia o ausencia puede indicar la situación en que se encuentra el cuerpo de agua.

\section{Requerimientos de la calidad del agua}

Los requerimientos de la calidad del agua varían de acuerdo con el uso que se les vaya a dar, por ejemplo para agricultura, pesca, propagación de vida silvestre, usos recreativos o industriales específicos o generación de energía. Algunas características del agua adecuadas para un fin 
pueden no serlo para otro. Es importante mencionar que no se debe confundir los requerimientos de la calidad del agua con los estándares de calidad del agua. Los primeros están basados en la experiencia del uso y los segundos son cantidades establecidas por instituciones gubernamentales (Arellano, 2002).

\section{Indices de calidad del agua:}

Los Índices de Calidad del Agua (ICA) se definen como la evaluación de su naturaleza química, física y biológica en relación con la calidad natural, los efectos humanos y usos posibles. Para simplificar la interpretación de los datos de su monitoreo, existen Índices de Calidad de Agua (ICA) e Índices de Contaminación (ICO), los cuales reducen una gran cantidad de parámetros a una expresión simple de fácil interpretación entre técnicos, administradores ambientales y el público en general. La principal diferencia entre unos y otros está en la forma de evaluar los procesos de contaminación y el número de variables tenidas en cuenta en la formulación del índice respectivo. En términos simples, un ICA es un número único que expresa la calidad del recurso hídrico mediante la integración de las mediciones de determinados parámetros de calidad del agua y su uso es cada vez más popular para identificar las tendencias integradas a los cambios en la calidad del agua. (Torres, Cruz, y Patiño (2009).

\section{Contaminación del agua}

El agua para consumo humano proviene de dos tipos de fuentes: las aguas superficiales y las aguas subterráneas o también llamados acuíferos.

Respecto a las aguas superficiales, puedo decir que estas son las que se encuentran sobre la superficie de la tierra como los ríos, lagos y lagunas. En cuanto a las aguas subterráneas, ellas se encuentran en el subsuelo por filtración y son el resultado del ciclo hidrológico. El agua proveniente de estas fuentes, debe ser tratada para el consumo humano o de otra manera, la población en general sufriría de graves enfermedades. La contaminación del agua se define como la presencia de sustancias u organismos extraños en un cuerpo de agua en tal cantidad y con tales características que le impiden su utilización con propósitos determinados (Arellano, 2009). Como sabemos ya, la contaminación del agua ocurre por la acción de carácter antropogénica y la acción de la 
naturaleza. Sin embargo, también conocemos dos tipos de tratamientos de aguas: el tratamiento de aguas residuales y el tratamiento de aguas para el consumo humano, este último lo analizaremos en este documento.

\section{Tratamiento de aguas para el consumo humano.}

El tratamiento de aguas se conoce como la forma más antigua que el ser humano ha conseguido para eliminar los residuos y mejorar la calidad en cuanto a olor, color, sabor y apariencia. Si hacemos un poco de historia, el agua se trataba con métodos muy sencillos como hirviéndola, exponiéndola al sol, sedimentándola o filtrándola a través de arena o grava para purificarla. Como lo muestra el siguiente esquema ilustrativo:

En la actualidad, las técnicas de uso general para el tratamiento de aguas residuales y de abastecimiento para consumo humano se complementan con procesos físicos, químicos o biológicos.

Tratamientos Físicos: son los que no generan sustancias nuevas sino que concentran los contaminantes al evaporar el agua o filtran los sólidos de tamaño considerable. Los más comunes son:

- Filtración

- Adsorción

- Aereación

- Floculación

- Clarificación o sedimentación

Tratamientos químicos: de este proceso resultan nuevas sustancias, los mas comunes son:

- Coagulación

- Desinfección

- Ablandamiento

- Oxidación

Tratamientos biológicos: se usan en este proceso organismos vivos para provocar cambios químicos (puede ser visto como tratamiento químico):

- Digestión aerobia

- Digestión anaerobia

Estos tratamientos tienen lugar en lo que se conoce como planta de tratamiento, cuya finalidad es acondicionar el agua para el consumo humano: 
La Filtración es el método más común para remover partículas pequeñas transportando el agua a través de material poroso. Por ejemplo, cuando el agua pasa a través de lechos de arena, las partículas son retenidas en los espacios que hay entre los granos o en la superficie de los mismos en el proceso llamado adsorción. Las partículas se detienen en la superficie de los granos y éstas son retenidas por las fuerzas de adsorción. De esta manera la filtración ayuda a controlar la contaminación biológica y la turbiedad, que es la medida de la opacidad del agua causada por materia suspendida y que reduce la efectividad de los compuestos para su desinfección. En algunos sistemas de filtración se forman en el material poroso capas que contienen microorganismos, algas, bacterias y materia orgánica. Este proceso de filtración ocurre de manera natural cuando las aguas superficiales se mueven a través del material poroso del suelo para recargar los mantos freáticos y son removidas las partículas contenidas por lo que el agua del subsuelo no requiere de ningún tratamiento posterior. Las tecnologías de filtración comúnmente utilizadas para el tratamiento de aguas son la filtración lenta a rápida en lechos de arena, sistemas sistemas rápidos o lentos se refieren a la cantidad de flujo por unidad de área. Los filtros se clasifican en función del material granular utilizado, como carbón-antracita o arena-carbón; en función de si son filtros por gravedad o por presión. Los sistemas de filtración se clasifican por la dirección del flujo de agua a través del filtro, en flujo ascendente y descendente (Arellano, 2002).

A continuación se muestran algunas técnicas de filtrado de agua para el consumo humano según la EPA- Agencia de protección ambiental de los USA. (2003):

Desinfección con cloro: es un proceso químico que mata organismos patógenos, existen dos tipos de desinfección por cloro: la primaria, donde se matan los organismos y la secundaria que mantiene un desinfectante residual para prevenir el crecimiento de más microorganismos en el sistema de distribución de agua. Desde hace años, el cloro en diferentes combinaciones como $\left(\mathrm{Ca}(\mathrm{ClO})_{2}\right.$ ), líquido $(\mathrm{NaClO})$ o como gas $\left(\mathrm{Cl}_{2}\right)^{2}$, se ha utilizado como desinfectante en diversos países (Arellano, 2002).

Desinfección con Ozono $\left(\mathrm{O}_{3}\right)$ para desinfectar el agua requiere de 
un periodo de contacto más corto que el cloro para eliminarlos patógenos, es un gas tóxico que se puede obtener haciendo pasar el oxígeno que se encuentra en el aire a través de dos electrodos, es un compuesto inestable que puede ser generado en el mismo lugar donde se encuentra y tiene una baja solubilidad en el agua, por lo que se debe obtener la máxima eficiencia al estar en contacto con el líquido. Una desventaja que presenta es que debe utilizarse un desinfectante secundario, ya que éste no mantiene residuos en el agua, además de que su costo es muy elevado (Arellano, 2002).

Radiación ultravioleta (UV): es otro sistema utilizado y muy efectivo para eliminar las bacterias y virus, pero también necesita de un desinfectante secundario por las mismas razones que el ozono. La radiación ultravioleta es útil para sistemas pequeños de tratamiento de aguas porque tiene una disponibilidad inmediata, no produce residuos tóxicos, su tiempo para contacto es corto y su equipo es sencillo para operar y darle mantenimiento. Una desventaja importante de esta técnica es que no se puede utilizar para agua con altos niveles de sólidos suspendidos, turbiedad, color o materia orgánica, ya que las sustancias que generan estas propie- dades pueden reaccionar o absorber la radiación ultravioleta reduciendo la eficiencia de la desinfección (Arellano, 2002).

Tratamiento de contaminantes orgánicos e inorgánicos: Existen diferentes sustancias orgánicas sintéticas que se han depositado en las fuentes de abastecimiento de agua, algunas de ellas son el tricloroetileno que forma parte de los compuestos orgánicos volátiles (COV). Las fuentes de suministro han sido contaminadas por la disposición inadecuada de residuos, depósitos de gasolina, uso de insecticidas y efluentes industriales. La contaminación inorgánica en las fuentes de abastecimiento de agua se debe principalmente a las sustancias que se encuentran en forma natural en el agua como el arsénico, el bario, radón, azufre y selenio. La industria contribuye con el depósito de metales que se filtran en el subsuelo. Los químicos inorgánicos también se presentan en el agua potable debido a la corrosión, que es el deterioro o destrucción de los sistemas de bombeo y distribución de agua por la acción química o física, cuyo producto se deposita en el agua. Estos sistemas están hechos de metales como el plomo, cadmio, zinc, cobre y fierro liberados como 
productos de la corrosión y pueden causar problemas a la salud. La corrosión también puede afectar la vida útil de los sistemas de distribución y bombeo y proporcionar un campo de cultivo ideal para microorganismos que provocan sabores y olores desagradables.

Para remover este tipo de contaminantes existen tecnologías tales como la coagulación, ósmosis inversa, intercambio iónico, alúmina activada y aereación, las cuales se discutirán en los siguientes apartados (Arellano, 2002).

Aireación y oxidación: En el tratamiento de aguas, aireación se refiere a cualquier proceso donde el agua y el aire se ponen en contacto para remover sustancias volátiles dentro y fuera del agua. En estas sustancias volátiles podemos incluir el oxígeno, bióxido de carbono, nitrógeno, sulfuro de hidrógeno, metano y otros compuestos que provoquen olores y sabores desagradables. La fuente de abastecimiento de agua es un factor importante a tomar en cuenta para decidir si la aireación es necesaria. Las aguas superficiales no requieren este tipo de tratamientos en virtud de que contienen altas concentraciones de oxígeno. Sin embargo carbono, metano, sulfuro de hidrógeno, fierro y manganeso, por lo que se recomienda este tratamiento para precipitar los últimos dos elementos. En el tratamiento de aguas se utiliza la oxidación para varios propósitos, ya que es una reacción en la cual las sustancias pierden electrones e incrementan su carga. Las sustancias oxidantes se utilizan para eliminar olores y sabores desagradables para remover el hierro y el manganeso y para clarificar el agua. Las sustancias químicas utilizadas más comúnmente como oxidantes y que resultan más efectivas en el tratamiento de aguas son: el dióxido de cloro, el ozono y el permanganato de potasio y cloro de las cuales las más utilizadas son las dos últimas (Arellano, 2002).

Tratamiento por métodos de adsorción: La adsorción se define como la atracción y acumulación de una sustancia sobre la superficie de otra. En el tratamiento de aguas los materiales de adsorción más utilizados son el carbón y la alúmina activados, que se utilizan para remover arsénico y contaminantes orgánicos. En esta técnica el uso del carbón activado ha sido recurrente como práctica común para eliminar contaminantes desde hace muchos años ya que es muy efectiva para absorber material por su superficie de gran tamaño, 
cada una de sus partículas contiene gran cantidad de poros donde éstas son retenidas y absorbidas; especialmente las sustancias orgánicas como los hidrocarburos. En el tratamiento de aguas se utiliza el carbón activado en forma de polvo y granular. En forma de polvo es insoluble y de color negro y se usa para controlar sabor y olor, se agrega en cualquier etapa del tratamiento de aguas a través de filtros. La alúmina activada es un alótropo del óxido de aluminio, en forma de material granular altamente poroso. En el tratamiento de aguas se utiliza para remover arsénico y exceso de iones de flúor. El procedimiento consiste en hacer pasar el agua a través de una columna rellena con este material, la remoción es una combinación entre adsorción con intercambio iónico. a utilización de la alúmina activada para remover arsénico y iones de flúor, requiere de periodos de regeneración. Cuando la alúmina se satura con arsénico y los iones de flúor, puede regenerarse haciendo pasar sosa caústica $(\mathrm{NaOH})$ a través del material Intercambio iónico. (Arellano, 2002).

El intercambio iónico se define como la transferencia de iones entre un medio sólido (resina) y una solución. Esta técnica es utilizada para remoción de cationes, lo que se conoce como ablandamiento. Como ya se había mencionado, la dureza del agua es causada principalmente por la presencia de iones de calcio y magnesio; también contribuyen el hierro, bario, aluminio y el estroncio. Las resinas utilizadas para intercambio iónico contienen elementos que intercambian iones de sodio. El ion hidronio está disponible en resinas, pero éste no es utilizado para ablandar aguas en fuentes de abastecimiento. Las resinas que generan cationes de sodio reemplazan los iones que provocan la dureza, por lo que la disminuyen, pero incrementan el contenido de iones de sodio.

La desmineralización es un proceso de intercambio iónico que remueve los sólidos disueltos en las fuentes de suministro de agua. Estos sólidos disueltos contienen tanto aniones como cationes, por lo que requieren los dos tipos de resinas. Las resinas utilizadas con propósitos de desmineralización presentan intercambio de iones hidronio y se dividen en ácidos fuertes y ácidos débiles. Lo mismo sucede con los iones oxhidrilo que se dividen en bases fuertes y débiles. El agua blanda que se genera en este proceso, puede ser mezclada con otra con un mayor contenido de sales, para obtener la calidad del agua requerida en cuanto a su contenido de sales. 


\section{El proceso de desmineralización} se utiliza para remover arsénico, bario, cadmio, cromo, flúor, plomo, mercurio, nitratos, selenio, plata, cobre, fierro, manganeso, sulfatos y zinc. Este proceso presenta muchas ventajas como son la baja inversión que se requiere y la simplicidad del proceso. Su mayor desventaja es el alto requerimiento químico para regenerar las resinas y disponer los residuos de estos procesos. Estos factores hacen que el intercambio iónico sea más adecuado para sistemas reducidos de tratamiento de agua. Los compuestos orgánicos disueltos, agentes oxidantes fuertes y sólidos suspendidos totales (SST) son contraproducentes en los sistemas de intercambio iónico. Los compuestos orgánicos pueden ser absorbidos en las resinas, el cloro pude ser removido por el carbón activado y los sólidos suspendidos pueden inhibir la transferencia de agua a través de la unidad de intercambio iónico y evitar así el contacto apropiado entre el agua y la resina de intercambio.

Procesos de membrana: Existen dos tratamientos que involucran procesos de membrana y que son utilizados normalmente para remover sales (desmineralización) del agua:
La ósmosis normal: dos soluciones que contienen diferentes concentraciones de minerales son separados por una membrana semipermeable. El agua se mueve a través de la membrana del lado donde la solución está más diluida hacia la parte de mayor concentración. Este fenómeno continúa hasta que la presión hidrostática en la solución de mayor concentración es suficiente para detener el flujo.

Ósmosis inversa: el flujo de agua que pasa a través de la membrana semipermeable es inverso por la aplicación de presión externa que contrarresta la presión hidrostática. Esto trae como resultado mayor concentración de minerales de un lado y menor concentración y agua pura en el otro lado.

Electrodiálisis: es la desmineralización de agua utilizando los principios de la ósmosis, pero con la influencia de un campo eléctrico de corriente directa. Los minerales se disocian en cationes y aniones cuando entra en el agua. El electrodo positivo llamado ánodo (+), atrae los aniones y el electrodo negativo llamado cátodo $(-)$, atrae los cationes. Existen dos tipos de membrana semipermeable selectiva utilizada en la electrodiá- 
lisis. Una que puede permear los cationes pero no los aniones y la otra puede permear los aniones pero no los cationes. Estas membranas se acomodan en capas, alternando las que permean cationes con las que permean aniones. El agua se alimenta en los espacios entre las membranas y se aplica un campo eléctrico de corriente directa entre las diferentes capas, lo que causa la migración de los iones hacia los electrodos opuestos y trae como consecuencia que los iones se concentren entre los espacios de membranas alternadas y en los demás espacios el agua desmineralizada, la cual es posteriormente extraída en diferentes chorros, uno que contiene los iones y el otro libre de los mismos.

El elemento esencial en el método de ósmosis inversa es la membrana semipermeable. Existen diferentes tipos de membranas semipermeables que serán utilizadas dependiendo de las características del agua que vaya a ser tratada. Los sólidos suspendidos, los disolventes orgánicos, el sulfuro de hidrógeno, el hierro, el manganeso y los agentes oxidantes pueden dañar las membranas. Las membranas de celulosa son susceptibles de ser atacadas por bacterias pero son resistentes al cloro. Las membranas de poliamida (nylon) no son blanco de ataques biológicos pero son sensibles al cloro. Por lo anterior, es necesario que el agua que entra a las unidades de electrodiálisis sea sometida a un tratamiento previo para eliminar los constituyentes indeseables. Se aconseja que el agua antes de este tipo de tratamiento tenga un pentre 5.0 y 6.5 para prevenir formación de hidróxidos y carbonatos, y que tenga niveles bajos de fierro y manganeso y agregar polifosfatos para inhibir la formación de sulfato de calcio $\left(\mathrm{CaSO}_{4}\right)$.

Estabilización: El agua potable que salga de una planta de tratamiento y que entre al sistema de distribución debe estabilizarse. Esto significa que no debe formar depósitos de sales o ser corrosiva bajo las temperaturas en que será distribuida. La manera más común de ajustar el $\mathrm{pH}$ del agua es adicionando polifosfatos o silicatos. La estabilización del agua se asocia al ajuste del $\mathrm{pH}$ para controlar la corrosión; por lo que debe haber suficientes iones de calcio para que se forme carbonato de calcio. En el agua con esta última característica se debe agregar hidróxido de sodio para que no haya un incremento de la dureza (Arellano, 2002). 
En muchos países del mundo, el agua dulce es antes un "bien público" que un Derecho fundamental del ser humano. Al permitir que el acceso y la distribución de agua sean dirigidos por mercados insaciables, la crisis mundial del agua seguramente se profundizará y el acceso al agua será aún más desigual.

En América latina, hoy se disfruta del $26 \%$ de los recursos hídricos del planeta, pero un $6 \%$ de la población mundial sólo dispone del 36\% del agua dulce disponible. Pero es evidente, que los problemas con el agua no se reducen únicamente a la situación geográfica, climática o demográfica de los países. La falta de recursos económicos genera las mayores desigualdades a la hora de enfrentarse a este problema. (Ríos, 2012)

Existe además una larga lista de disputas motivadas por los recursos hídricos, de enfrentamientos por el acceso a suministros adecuados. Las aguas superficiales, como ríos, lagos o mares interiores son compatibles con la noción tradicional de frontera, pero no sucede lo mismo cuando hablamos de aguas subterráneas, numerosos acuíferos son compartidos por el subsuelo de dos o más estados, cualquier acción unilateral no concertada puede provocar efectos negativos para el estado vecino. (Ríos, 2012)

Hacerse con el control del agua dulce no es sólo objetivo de los estados, el agua, como elemento escaso e imprescindible para la vida, el llamado "oro azul" es una mercancía muy preciada por grandes empresas transnacionales, estas empresas en numerosas regiones del mundo gestionan el agua, le ponen un precio y sólo abastecen a quién pueda pagarla. En estos casos el agua no separa países ni distingue regiones, el agua traza la frontera entre las sociedades ricas y las empobrecidas. Las diversas actividades agrícolas, ganaderas, industriales y recreacionales del ser humano han traído como consecuencia la contaminación de las aguas superficiales con sustancias químicas y microbiológicas, además del deterioro de sus características estéticas. El tratamiento de aguas está regido por una serie de normas que indican o fijan los límites generales aceptables para las impurezas de las aguas que están destinadas al abastecimiento público (condiciones mínimas de calidad física, química y bacteriológica) (Canto, 1977). Estas normas no deben considerarse como un criterio que evaluación o control de las operaciones de las plantas de tratamiento 
sino como las especificaciones generales para la aceptación del producto, ya que cuando el tratamiento de las aguas está bien controlado, se pueden obtener mejores resultados que los establecidos en las normas. Frecuentemente, el agua es desinfectada antes de que entre al sistema de distribución para asegurar que los contaminantes microbianos peligrosos sean eliminados. El cloro, compuestos de cloro, o dióxidos de cloro son los agentes de uso más común porque son desinfectantes bastante eficaces y las concentraciones residuales pueden ser mantenidas por el sistema de agua. (EPA, 2003). Cabe aclarar que si bien el proceso de desinfección es considerado como uno de los I avances científicos más importantes del siglo XX, cabe resaltar el hecho que si este proceso no se lleva adecuadamente con los protocolos establecidos, "en algunos casos los mismos desinfectantes pueden reaccionar con los materiales de ocurrencia natural dentro del agua para formar productos secundarios de manera involuntaria, los cuales pueden representar un riesgo para la salud" (EPA 2003), por lo tanto es de imprescindible necesidad que el personal encargado de estos procesos de potabilización del agua sean capacitados adecuadamente a fin de lograr un personal idóneo en este procesos especifico, que es precisamente el motor de toda la red de distribución de agua potable, y es el responsable de una adecuada salud en los usuarios. En la actualidad muchos gobiernos llegaron a acuerdos con el sector privado, con el argumento de poder así resolver los problemas de acceso al agua de muchos millones de personas. Las aguas superficiales, como ríos, lagos o mares interiores son compatibles con la noción tradicional de frontera y debido a factores climáticos (escasas precipitaciones) y otros factores (económicos, políticos...) y serios problemas de desertización, estos están asolando la región latinoamericana, situación que provoca que la pobreza esté extendida en cada región y sea foco de constantes problemas sociales y generador de tensiones entre los distintos países afectados. (Ríos, 2012).

Finalmente, hay que tener muy en cuenta la degradación medioambiental que están sufriendo los ríos de la región y las principales fuentes de contaminación del agua en tres países involucrados en el conflicto (Bolivia, Ecuador y Perú) son las aguas no tratadas, el uso de agroquímicos, la actividad minera en la región andina, altamente contaminante y la explotación de hidrocarburos en la Amazonia. A fin de lograr en 
Colombia un uso eficiente e integrado del recurso hídrico, el ministerio del medio ambiente, en el año 2010, diseño la política para la gestión integral del recurso hídrico, la cual busca regular en diferentes etapas la utilización del agua; teniendo en cuenta la importancia que este líquido radica en nuestra vida y en nuestro país, este documento ha buscado abarcar diferentes aspectos sociales y económicos, por lo que se fundamenta ocho principios que buscan un manejo adecuado y racional de este recurso mediante los siguientes principios:

Como primer principio orientador de la política en mención, se destaca el hecho de considerar al agua como un "bien de uso público: el agua es un bien de uso público y su conservación es responsabilidad de todos" (Ministerio ambiente, 2010); también se considera que el agua debe tener un "uso prioritario: El acceso al agua para consumo humano y doméstico tendrá prioridad sobre cualquier otro uso y en consecuencia se considera un fin fundamental del Estado. Además, los usos colectivos tendrán prioridad sobre los usos particulares" (Ministerio ambiente, 2010); en el documento también se considera al agua como un "factor de desarrollo: El agua se mico del país por su contribución a la vida, a la salud, al bienestar, a la seguridad alimentaria y al mantenimiento y funcionamiento de los ecosistemas" (Ministerio ambiente, 2010); también se considera la "integralidad y diversidad: La gestión integral del recurso hídrico armoniza los procesos locales, regionales y nacionales y reconoce la diversidad territorial, eco sistémica, étnica y cultural del país, las necesidades de las poblaciones vulnerables (niños, adultos mayores, minorías étnicas), e incorpora el enfoque de género" (Ministerio ambiente, 2010).

Además de diseñar las estrategias de utilización del agua en todo el país, los principios de esta ley también incluyen la "unidad de gestión: La cuenca hidrográfica es la unidad fundamental para la planificación y gestión integral descentralizada del patrimonio hídrico" (Ministerio ambiente, 2010); buscando también que dentro de estos principios se realice el "ahorro y uso eficiente: El agua dulce se considera un recurso escaso y por lo tanto, su uso será racional y se basará en el ahorro y uso eficiente" (Ministerio ambiente. 2010); siendo congruentes con el primer principio mencionado en este documento, también se busca la "participación y equidad: La gestión del agua se orientará bajo un enfoque 
participativo y multisectorial, incluyendo a entidades públicas, sectores productivos y demás usuarios del recurso, y se desarrollará de forma transparente y gradual propendiendo por la equidad social" (Ministerio ambiente, 2010); finalmente se establece que los usuarios y beneficiarios de este recurso deben tener acceso a la "información e investigación: El acceso a la información y la investigación son fundamentales para la gestión integral del recurso hídrico" (Ministerio ambiente. 2010).

\section{Conclusion}

El agua es indispensable para la vida en la tierra así como para el desarrollo industrial y agrícola de las sociedades humanas. Desde el inicio de las organización humana el hombre ha procurado mejorar y aumentar sus recursos de agua y se ha preocupado por hacer inofensiva para la salud las aguas usadas. Que se haya conseguido la desinfección con cloro de los suministros de agua publica es uno de los mayores logros en el campo de la salud pública del siglo $X X$, esto permitió la eliminación de enfermedades como el cólera, tifoidea y disentería. Sin embargo se expresa constantemente una preocupación sobre los efectos potencialmente adversos de los subproductos de la desinfección, entre estos trihalometanos (Sierra y Serna, 2013).

Los procesos de tratamiento actuales deben contar con un enfoque distinto al prevalente en las décadas pasadas. Este enfoque es sin duda más sofisticado y posiblemente más costoso que el tradicional y requiere de una operación más cuidadosa. La mayoría de los países con alto grado de desarrollo econó-mico y social ya lo tienen implementado; no así la América Latina, donde todavía, en algunos casos, perviven conceptos abolidos que conducen a conservar parámetros de calidad riesgosos para la salud, pues con ellos no se puede producir agua verdaderamente potable dentro de los estándares actuales. La calidad del agua que se libra al consumo es uno de los aspectos que siempre debe ser motivo de preocupación para las autoridades que trabajan en el campo del agua potable, no solamente bajo la óptica de que obligatoriamente deben cumplirse los reglamentos que regulan en la materia, sino pensando además en brindar a la población un producto sano y saludable, vital para el desarrollo de todas las actividades humanas. La calidad del agua y su acceso es un problema evidente, debido a que la cantidad del recurso hídrico es limitada, de ahí 
que se tenga que potabilizar aguas residuales y servidas. Países como Colombia que se encuentra en vía de desarrollo, presentan limitantes económicos para el tratamiento del aguas para el consumo humano, como el de adecuar la calidad a las normas propias del uso. Hoy en día, el agua reúne las características organolépticas, físicas, químicas y microbiológicas, además de las que tienen que ver con sustancias toxicas, permitiendo así su consumo y garantizando su calidad.

Atendiendo a ese objetivo es que se debe promover la redacción de las leyes, regulaciones y estándares de calidad de agua de carácter nacional, tomando como base las «Guías para la Calidad del Agua Potable» de la Organización Mundial de la Salud (2006).

Todos debemos finalmente mantener y conservar los ecosistemas acuáticos existentes, su buen uso y gestión eficaz apoyada en el ahorro, la reutilización y la no contaminación del agua, nos llevará una gestión integral del recurso hídrico.

En el mundo, el agua ha sido sobre utilizada y es por esta razón es que actualmente muchos países cuentan con un déficit de este recurso, ante esta situación en muchas regiones se presentan disputas por este líquido vital; sin embrago el problema de falta de agua no obedece exclusivamente a la falta física de este recurso, sino que más bien obedece a la falta de planeación en la utilización del agua, ya que es muy bueno encontrar leyes y decretos que velan por la protección y uso eficiente del agua, sin embrago cuando observamos la realidad nos damos cuenta que no se respetan estas leyes y que incluso los mismos gobiernos las excluyen en pro de obtener mayores beneficios económicos que se representan en regalías. A nivel de nuestro país se refleja claramente todos los problemas ambientales y de uso del agua, tal es el hecho que por ejemplo la Corporación Autónoma Regional del Cauca (2010), realmente no aplica las normas establecidas por la legislación, y más bien se ha dedicado a cobrar unos recursos económicos si tener en cuenta muchos aspectos técnicos que son relevantes en la conservación de los recursos naturales, con esto quiero dar a conocer que realmente las instituciones se han dedicado a la gestión de recursos económicos, dejando de lado la gestión adecuada de loa recursos naturales y el ambiente en general. Todo proceso de intervención del hombre sobre la naturaleza causa 
un impacto en menor o mayor proporción, y eso lo estamos viviendo, por ejemplo con los fenómenos del niño y de la niña, en donde se ha presentado un descontrol total del clima y en unos momentos hay demasiada agua que afecta que afecta nuestras vidas al presentarse procesos de inundación que tantas pérdidas materiales y humanas han causado en nuestro país y en general alrededor del mundo, y por otro lado los periodos de extrema sequía que en muchas regiones han hecho que ríos enteros pierdan su caudal afectando de igual forma o peor la vida en todo el planeta, por lo tanto es muy importante que todos aportemos a la protección de los recursos naturales mediante el uso eficiente de los mismos, a fin de garantizar un futuro promisorio para nuestros descendientes.

Como conclusión final cabe destacar el hecho que el agua para el consumo humano debe contar con una especificaciones generales de potabilidad ya establecidas en muchas tablas de análisis, y que es de vital importancia la toma de conciencia por un lado de los gobernantes a fin de suministrar a las comunidades ya sean urbanas o rurales un agua optima e inocua para su consumo, y por parte de las comunidades consu- midoras de este recurso la procura de disminuir los procesos contaminantes de este recurso que finalmente representa un $70 \%$ de nuestra vida, y que sin el cual no podríamos vivir, esta característica tan importante como es el sustento de nuestra propia vida debería ser suficiente motivación para emprender procesos de preservación de este recursos y su potabilización para nuestro consumo diario.

\section{Referencias}

Agencia Andaluza de Cooperación Internacional para el Desarrollo. (2013). Solidaridad andalucia. Recuperado de http://www.solidaridadandalucia.org/derecho_ agua/index.html

Arellano, J. (2002). Introducción a la Ingeniería Ambiental. Mexico, D. F.: Alfaomega.

Canto, J. (1977). Tratamiento de Aguas para Abastecimiento Publico. Barcelona: Tecnico Asociados.

Corporación autónoma regional del cauca - CRC. (2010). Caracterización ambiental plan departamental de aguas y saneamiento básico departamento del cauca. Recuperado de http://www.crc. gov.co/files/ConocimientoAmbiental/AMB_PDA_CAUCA.pdf 
EPA. Agencia de protección ambiental de los estados unidos. (2003). El agua del grifo lo que usted debe saber. Recuperado de http://cedum.umanizales.edu. $\mathrm{co}$

Ministerio deAmbiente. (2010). Política nacional para I gestión integral del recurso hídrico. Recuperado de http://www.minambiente.gov. co/documentos/5774_240610_ libro_pol_nal_rec_hidrico.pdf.pdf

OMS. Organización mundial de la salud. (2006). Guías para la calidad del agua potable. Volumen 1. Recuperado de http:// cedum.umanizales.edu.co
Rios, D. (2012). Riesgos biológicos y subproductos de la desinfección en el agua de bebida. Recuperado de http://www.bvsde.paho.org/ bvsacd/cd59/danilorios.pdf

Sierra, L. y Serna, S. (2013). Tratamientos de agua para abastecimiento. Recuperado de http://www. slideshare.net/Imsf/tratamiento-deaguas-para-

Torres, P., Cruz, C. y Patiño, P. (2009). Índices de calidad de agua en fuentes superficiales utilizadas en la producción de agua para consumo humano. Una revisión crítica. Revista Ingenierías Universidad de Medellín. 8, (15) especial, (pp. 79-94). 